\title{
A PRÁTICA GRUPAL COM JOVENS NA PSICOLOGIA: REVISÃO INTEGRATIVA DE LITERATURA
}

THE GROUP PRACTICE WITH YOUNG PEOPLE IN PSYCHOLOGY: INTEGRATIVE LITERATURE REVIEW

\section{LA PRÁCTICA GRUPAL CON JÓVENES EN LA PSICOLOGÍA: REVISIÓN INTEGRATIVA DE LITERATURA}

\author{
Larissa Franco Severino* \\ Renata Fabiana Pegoraro* \\ Eliane Regina Pereira**
}

\begin{abstract}
RESUMO
A compreensão sobre práticas grupais com jovens e sua finalidade na Psicologia parte de diversas perspectivas e está prevista entre as habilidades e competências profissionais. Este artigo busca compreender, com base em uma revisão integrativa de literatura, como os grupos com jovens são caracterizados e constituídos pelas produçōes de artigos científicos em Psicologia. Foram realizadas buscas nas bases Scielo, Pepsic e Adolec e, mediante critérios de inclusão e exclusão, foram recuperados dez artigos, cuja análise permitiu ressaltar os grupos como espaço: (a) de circulação da palavra; (b) de troca e possibilidade de transformação; (c) terapêutico. Ainda há poucas publicações sob a forma de artigos envolvendo a prática grupal com jovens. Esses artigos frisaram como principal característica grupal proporcionar um espaço de fala e trocas entre os sujeitos inseridos. Destacase certa naturalização dos sujeitos participantes dos grupos, visto que suas histórias de vida e suas condiçôes sociais deixaram de ser ressaltadas.
\end{abstract}

Palavras-chave: Juventude. Grupos. Psicologia. Políticas Públicas.

\footnotetext{
Texto recebido em 24 de janeiro de 2019 e aprovado para publicação em 3 de setembro de 2019.

Doutoranda do Programa de Pós-Graduação em Psicologia da Universidade Federal de Santa Catarina (UFSC), na área Psicologia Social e Cultura, mestra em Psicologia pela Universidade Federal de Uberlândia (UFU). Endereço: Rua Lauro Linhares, 1390, ap. 607 B, - Trindade, Florianópolis-SC, Brasil. CEP: 88036-002. Telefone (34) 99187-0735. Lattes: http:// lattes.cnpq.br/6414656123240536._E-mail: larissa1793@hotmail.com.

"* Pós-doutorado em Psicologia Social pela Pontifícia Universidade Católica de São Paulo (PUC-SP), doutora em Psicologia pela Universidade de São Paulo (Campus Ribeirão Preto), docente no Instituto de Psicologia da UFU, atua na área de Psicologia e Saúde, com ênfase em Psicologia e Políticas Públicas de Saúde/Saúde Mental. Endereço: Curso de Graduação em Psicologia - Universidade Federal de Uberlândia, Campus Umuarama, Avenida Maranhão, 1668, bloco 2C, sala 47 - Bairro Umuarama, Uberlândia-MG, Brasil. CEP: 38405-318. Telefone: (34) 3225-8509. Lattes: http://lattes.cnpq.br/4823645280355146. E-mail: rfpegoraro@yahoo.com.br.

*** Pós-doutorado em Psicologia Social pela PUC-SP, doutora em Psicologia pela UFSC, professora no Departamento de Psicologia e no Programa de Pós-Graduação em Psicologia da UFU, atua na área da Psicologia da Saúde, com ênfase em Psicologia Social e nos Processos de Criação em Contextos de Saúde, atua principalmente com os temas constituição do sujeito, processos de criação, potência de ação, oficinas estéticas, promoção e prevenção em saúde, práticas grupais. Endereço: Curso de Graduação em Psicologia - Universidade Federal de Uberlândia, Campus Umuarama, Avenida Maranhão, 1668, bloco 2C, sala 31 - Bairro Umuarama, Uberlândia-MG, Brasil. CEP: 38405-318. Telefone: (34) 3225-8509. Lattes: http://lattes.cnpq. br/0023990232502452. E-mail: pereira.elianeregina@gmail.com.
} 


\begin{abstract}
The understanding about group practices with young people and their purpose in Psychology has many standpoints, being expected among other professional skills and abilities. This article attempts to understand, by conducting an integrative literature review, how groups with young people are characterized and constituted by the making of Psychology scientific papers. We searched Scielo, Pepsic and Adolec databases and, through inclusion and exclusion criteria, 10 articles were retrieved, which analysis allowed us to point out the groups as a space of: (a) word circulation; (b) exchange and possibility of transformation; (c) therapeutic space. There are still few papers concerning group practice with young people. They stressed as the main group characteristic the fact that it provides a space for speech and exchanges between the inserted subjects. We point out a certain naturalization of the participants of the groups, once their life histories and social conditions ceased to be highlighted.
\end{abstract}

Keywords: Youth. Groups. Psychology. Public policies.

\title{
RESUMEN
}

La comprensión sobre prácticas grupales con jóvenes y su finalidad en la Psicología parte de diversas perspectivas y está prevista entre las habilidades y competencias profesionales. Este artículo busca comprender, a partir de una revisión integrativa de literatura, cómo los grupos con jóvenes son caracterizados y constituidos por las producciones de artículos científicos en Psicología. Se realizaron búsquedas en las bases Scielo, Pepsic y Adolec y mediante criterios de inclusión y exclusión se recuperaron 10 artículos, cuyo análisis permitió resaltar a los grupos como espacio: (a) de circulación de la palabra; (b) de cambio y posibilidad de transformación; (c) espacio terapéutico. Todavía hay pocas publicaciones en forma de artículos que involucren prácticas grupales con jóvenes. Estos artículos destacaron como la característica principal del grupo proporcionar un espacio de discusión e intercambios entre los sujetos participantes. Se destaca cierta naturalización de los sujetos participantes de los grupos, una vez que sus historias de vida y condiciones sociales no fueron enfatizadas.

Palabras clave: Juventud. Grupos. Psicología. Políticas públicas.

\section{INTRODUÇÃO}

$\mathrm{N}$

o decorrer da História da Psicologia, a literatura sobre práticas grupais tem natureza múltipla e diversificada. $\mathrm{O}$ caráter de sua multiplicidade está relacionado à variedade de enfoques teóricos, embasamentos epistemológicos e metodológicos. Nesse cenário, a constituição do grupo como 
objeto de estudo na Psicologia configura-se como um amplo espectro tanto de possibilidades teóricas como de propostas de intervençôes.

Por meio de um breve resgate etimológico sobre a palavra grupo, duas são as possíveis origens do termo (Tchiedel, 1998, apud Zanella \& Pereira, 2001): o vocábulo grop, que vem do provençal, que significa nó, e o termo Kruppa, em germânico, que significa forma arredondada. Percebe-se que a genealogia do termo já carrega consigo a noção de conjunto, ou seja, de concentração de algo ou alguém.

Apesar de a genealogia do termo grupo bem como grupo como vocábulo permearem significados relativos à união desde o século XVII, foi apenas no século XX que o termo se constituiu como instituição. Grupo como instituição é compreendido por Barros (2007, p. 95) como "uma composição de linhas que ao se atravessarem produzem campos de saber, redes de poder, especialismo".

Muitos autores já se propuseram a investigar grupo nas Ciências Sociais e Humanas. Barros (2007), Lane (1984), Martín-Baró (1996) e Petrovski (1984) afirmam que o grupo é fundamental para conhecermos o ser como ser social, imerso em um determinado momento histórico, inserido em uma cultura e, com base nisso, promovermos açôes com potencial para transformação.

No cenário prático, quando pensamos sobre o surgimento da prática grupal, o grupo como campo de atuação e pesquisa teve seu início quando Joseph Henry Pratt começou a utilizá-lo como prática de modalidade de tratamento, sem qualquer rigor metodológico, impulsionado pelas suas próprias intuições (Boris, 2014). De acordo com Maireno, Sei e Zanetti (2016), essas intervenções grupais tinham caráter de persuasão e de reeducação emocional, com objetivo de oferecer cuidados clínicos bem como orientação de atitudes positivas diante do tratamento clínico.

É preciso destacar que o desenvolvimento teórico, prático e de pesquisa, bem como a investigação e articulação dos conhecimentos sobre grupos têm proporcionado à Psicologia, assim como aos profissionais vinculados a essa área, a oportunidade de criar, pensar e conduzir ferramentas de trabalho com inúmeros sujeitos, em diferentes contextos, como na educação (Fernandes, 2015), saúde (Dalla Vecchia, 2011), socioeducativo (Rodrigues, 2017), entre outros. Uma das formas de consolidação do trabalho com grupo tem sido enfatizada na formação do psicólogo para atuar com essa modalidade de atendimento. As Diretrizes curriculares nacionais (DCN) para os cursos de Psicologia (Resolução no 5, 2011), que regulamentam a formação do psicólogo, preveem, entre as habilidades e competências profissionais a serem desenvolvidas durante a graduação, aquelas voltadas à "atuação em diferentes contextos, considerando as necessidades sociais 
e os direitos humanos, tendo em vista a promoção da qualidade de vida dos indivíduos, grupos, organizações e comunidades" (art. $3^{\circ}$, inciso V).

Em relação às DCN, é necessário enfatizar que destacamos a última versão destas, entretanto sua primeira versão surgiu em 2004 e, desde essa época, ela já tinha previsto, como habilidades e competências profissionais para o estudante de Psicologia, a atuação com grupos. Entre os possíveis campos de atuação em grupo na Psicologia, as DCN destacam três ênfases:

1) Psicologia e processos educativos;

2) Psicologia e processos de prevenção e promoção da saúde; e

3) Psicologia e processos clínicos.

De acordo com Martínez e Paterna (2010), são principalmente três os campos que têm produzido mais elaborações sobre o tema dos grupos: o das organizaçôes, o da saúde e o educativo.

A iniciativa de enfatizar, neste artigo, estudos envolvendo jovens parte da compreensão de que, no processo de constituição do jovem, da jovem, segundo Vigotski (1996), existe um novo que surge em seu desenvolvimento, a possibilidade de abstração e formação de conceitos, e isso se deve à vida social, desenvolvimento cultural e atividade laboral. Para Vigotski, "A passagem ao pensamento em conceitos abre diante do adolescente o mundo da consciência social objetiva, o mundo da ideologia social" (Vigotski, 1996, p. 64, tradução nossa). Momento esse que se formam as concepções sobre a vida, sociedade, pessoas, enfim, sobre seu mundo exterior e sua realidade interna, desenvolvendo a autopercepção e percepções sobre o mundo.

Partindo da concepção de que o grupo é um espaço de reflexão em que os sujeitos participantes são interativos, ele se torna importante estratégia para possibilidade de (re)significação das experiências e (re)criação de si, além de promover qualidade de vida e prevenção de agravos a aspectos da vida dos jovens, das jovens.

Em consonância, as Diretrizes nacionais para a atenção integral à saúde de adolescentes e jovens na promoção, proteção e recuperação da saúde (Ministério da Saúde, 2010) ressaltam que "as atividades grupais de Educação em Saúde têm primazia, nessa faixa etária, embora o atendimento individual seja importante e necessário" (p. 79). Dessa maneira, alcançando um número maior de envolvidos, podemos até mesmo refletir sobre criações e construções de redes de proteção social que garantam os direitos desse público. 
Ao ampliarmos as possibilidades de diálogos e temas com jovens e adolescentes por meio de intervençôes coletivas, permitimos que eles e elas se diferenciem diante do que surge. Desse modo, ressaltamos a importância da intervenção grupal com jovens, já que "o grupo parte tanto da pluralidade de sujeitos que o compõem quanto produz pluralidade, à medida que os sujeitos singularizam/ subjetivam o que no grupo se desenrola" (Zanella, \& Pereira, 2001, p. 107). Dessa maneira, podemos buscar a superação das concepções universais, naturais e patologizantes, para, de maneira curiosa, mergulhar em seus discursos e levantar questionamentos na tentativa de suscitar provocaçóes sobre o que estiver sendo dialogado, levando em consideração o momento histórico, a cultura inserida e nosso sistema de produção.

Assim, com base no pressuposto da diversidade e pluralidade de concepções de grupo dentro da Psicologia, bem como sua importância como ferramenta de atuação, principalmente com jovens em seus múltiplos contextos, surgiu uma questão: como as produções de artigos científicos brasileiros na Psicologia se caracterizam e se constituem em relação à perspectiva grupal com jovens?

Por fim, considerando a atualidade e a pertinência das temáticas envolvidas e aqui expostas, este artigo propõe uma revisão integrativa de literatura de artigos publicados em língua portuguesa na área da Psicologia sobre como os estudos caracterizam e constituem a atuação grupal com jovens. Nesta revisão, buscamos enfatizar estudos empíricos que exploram sobre o processo de constituição do grupo com jovens.

\section{METODOLOGIA}

\subsection{A constituição do processo de revisão integrativa}

Realizamos uma revisão integrativa de literatura que pode ser definida como um estudo com coleta de dados, por meio de levantamento bibliográfico de determinada temática atual, "de modo a identificar, analisar e sintetizar resultados de estudos independentes sobre o mesmo assunto" (Souza, Silva, \& Carvalho, 2010, p. 104).

Primeiramente, elaboramos a pergunta norteadora para o estudo: "Como se caracterizam e se constituem as produções de artigos científicos em Psicologia sobre grupos com jovens?”. Posteriormente, no dia 5 de setembro de 2018, realizamos a busca nas bases indexadas Scientific Electronic Library On-line (Scielo), Biblioteca Virtual em Saúde do Adolescente (Adolec) e no Portal de Periódicos Eletrônicos de Psicologia (Pepsic), consideradas amplas, diversas e 
relacionadas com os conteúdos da pergunta norteadora. Para a localização das publicaçôes, combinamos os seguintes descritores: jovem, jovens, juventude, juventudes, grupo, grupos e Psicologia.

Para realizarmos a seleção dos títulos, usamos como critérios de inclusão: artigos científicos completos, redigidos em língua portuguesa, disponíveis online e publicados entre 2008 e 2018. Os períodos de 10 ou 5 anos são os mais sugeridos para realização de estudos de revisão (Scorsolini-Comin, 2014).

$\mathrm{Na}$ busca, foram encontrados um total de 1.034 artigos (873 na Adolec, 93 na Scielo e 68 na Pepsic). Logo, para a seleção da amostra, fizemos primeiramente a leitura dos títulos e como critérios de exclusão, consideramos:

1) teses e dissertações;

2) artigos que não estavam disponíveis on-line;

3) artigos que não estavam na língua portuguesa;

4) artigos teóricos;

5) artigos que não respondiam à pergunta norteadora;

6) artigos que não consideraram exclusivamente os jovens como sujeitos dos estudos;

7) artigos que não eram da área de Psicologia;

8) artigos que não consideraram o grupo como metodologia;

9) artigos que compreenderam o grupo como procedimento de pesquisa e não discutiram a prática grupal, como estudos com desenho caso-controle, grupos focais e grupos de dinâmicas.

Aplicados tais critérios, ocorreram 787 exclusões, e 247 títulos foram selecionados para leitura dos resumos.

Após a leitura dos resumos, dos 247 artigos selecionados, foram eliminados 17 por repetição e 207 pela aplicação dos critérios de exclusão (descritos no parágrafo anterior), restando, portanto, 23 artigos para leitura na íntegra. Por fim, após a leitura na íntegra dos 23 artigos, também pela aplicação dos critérios de exclusão, foram definidos integrantes de nossa amostra 10 artigos, sendo 6 da Adolec, 3 do Pepsic e 1 da Scielo, os quais efetivamente respondiam à pergunta norteadora. $\mathrm{O}$ processo da revisão integrativa realizada pode ser melhor observado na tabela 1 : 
Tabela 1 - Processo de recuperação dos artigos conforme as bases de dados

\begin{tabular}{|c|c|c|c|c|c|c|c|c|}
\hline $\begin{array}{c}\text { Bases de } \\
\text { dados }\end{array}$ & $\begin{array}{c}\text { Número } \\
\text { de artigos } \\
\text { localizados }\end{array}$ & $\begin{array}{l}\text { Eliminados } \\
\text { após leitura } \\
\text { dos títulos }\end{array}$ & $\begin{array}{l}\text { Número } \\
\text { de artigos } \\
\text { para } \\
\text { leitura dos } \\
\text { resumos }\end{array}$ & $\begin{array}{l}\text { Eliminados } \\
\text { por } \\
\text { repetição }\end{array}$ & $\begin{array}{l}\text { Eliminados } \\
\text { por } \\
\text { critérios de } \\
\text { exclusão }\end{array}$ & $\begin{array}{l}\text { Eliminados } \\
\text { após } \\
\text { leitura do } \\
\text { resumo }\end{array}$ & $\begin{array}{c}\text { Recuperados, } \\
\text { leitura na } \\
\text { íntegra }\end{array}$ & $\begin{array}{c}\text { Amostra } \\
\text { final }\end{array}$ \\
\hline
\end{tabular}

\begin{tabular}{ccccccccc}
\hline Adolec & 873 & 787 & 86 & 7 & 69 & 76 & 10 & 6 \\
Pepsic & 68 & - & 68 & 5 & 54 & 59 & 9 & 3 \\
Scielo & 93 & - & 93 & 5 & 84 & 89 & 4 & 1 \\
Total & 1034 & 787 & 247 & 17 & 207 & 224 & 23 & 10 \\
\hline
\end{tabular}

Fonte: elaborado pelas autoras.

\section{RESULTADOS E DISCUSSÕES}

\subsection{Caracterização geral das publicações}

As publicações que abordam sobre práticas e processos grupais com jovens na Psicologia (quadro 1) têm uma prevalência de estudos na Revista da SPAGESP $(\mathrm{n}=3)$, a qual se refere à Sociedade de Psicoterapias Analíticas Grupais do Estado de São Paulo, seguida da Revista Psicologia e Saúde (n=2) e Psicologia Revista, da PUC-SP ( $\mathrm{n}=2)$. Os periódicos Estilos Clinicos, Revista Brasileira de Crescimento e Desenvolvimento Humano e Psicologia \& Sociedade constaram apenas de uma publicação cada. O maior número de estudos na Revista SPAGESP pode ser compreendido por se tratar de uma publicação que tem como uma de suas principais temáticas o grupo. É importante enfatizar que, desses 6 periódicos, apenas 3 não são específicos da área de Psicologia (SPAGESP, Estilos Clínicos e Revista Brasileira de Crescimento e Desenvolvimento Humanos), porém suas possibilidades de temas dão abertura para temáticas envolvendo essa área de conhecimento. Esses dados podem ser mais bem observados no quadro 1, a seguir. 
Quadro 1 - Caracterização dos artigos recuperados quanto ao periódico, ano de publicação e classificação do estudo

\begin{tabular}{|c|c|c|c|c|}
\hline Artigo & Autor & Ano & Periódico & Tipo de estudo \\
\hline $\mathrm{A} 1$ & Souza & 2011 & Revista SPAGESP & $\begin{array}{l}\text { Relato de } \\
\text { experiência }\end{array}$ \\
\hline $\mathrm{A} 2$ & Rosário & 2010 & Revista SPAGESP & $\begin{array}{l}\text { Relato de } \\
\text { experiência }\end{array}$ \\
\hline A3 & Cunha, \& Lima & 2013 & Estilos Clínicos & $\begin{array}{l}\text { Relato de } \\
\text { experiência }\end{array}$ \\
\hline A4 & $\begin{array}{c}\text { Silva, Silva, Sicari, } \\
\text { \& Pereira }\end{array}$ & 2014 & $\begin{array}{c}\text { Revista Psicologia e } \\
\text { Saúde }\end{array}$ & $\begin{array}{l}\text { Pesquisa- } \\
\text { intervenção }\end{array}$ \\
\hline A5 & $\begin{array}{l}\text { Vieira, Dias, \& } \\
\text { Pereira }\end{array}$ & 2016 & $\begin{array}{c}\text { Revista Psicologia e } \\
\text { Saúde }\end{array}$ & $\begin{array}{l}\text { Pesquisa- } \\
\text { intervenção }\end{array}$ \\
\hline A6 & $\begin{array}{c}\text { Carvalho, } \\
\text { Medina, Bossetto, } \\
\text { \& Cruz }\end{array}$ & 2008 & Psicologia Revista & $\begin{array}{l}\text { Relato de } \\
\text { experiência }\end{array}$ \\
\hline A7 & Souza, \& Santos & 2009 & $\begin{array}{c}\text { Revista Brasileira } \\
\text { de Crescimento e } \\
\text { Desenvolvimento } \\
\text { Humano }\end{array}$ & Estudo empírico \\
\hline A8 & $\begin{array}{l}\text { Adrião, Menezes, } \\
\text { Souza, \& Falcão }\end{array}$ & 2017 & Psicologia \& Sociedade & $\begin{array}{c}\text { Pesquisa- } \\
\text { intervenção }\end{array}$ \\
\hline A9 & Sardenberg & 2008 & Psicologia Revista & $\begin{array}{l}\text { Relato de } \\
\text { experiência }\end{array}$ \\
\hline A10 & Moretto, \& Terzis & 2013 & Revista SPAGESP & $\begin{array}{c}\text { Pesquisa- } \\
\text { intervenção }\end{array}$ \\
\hline
\end{tabular}

Fonte: elaborado pelas autoras.

Em relação ao ano de publicação, podemos perceber que não houve concentração de publicaçóes. Os anos de 2013 e de 2008 se sobressaem com duas publicaçôes cada, e os anos de 2012, 2015 e 2018 não apresentaram nenhuma publicação envolvendo a temática proposta neste estudo.

Prevaleceram estudos do tipo relato de experiência (quadro 1). Faz-se necessário ressaltar que apenas Carvalho, Medina, Bossetto e Cruz (2008) denominaram seu estudo como relato de experiência. Os demais, assim classificados, foram nomeados pelas autoras, pois enfatizavam casos de experiências profissionais que recorreriam às práticas grupais em diferentes contextos. Dos 4 estudos considerados como pesquisa-intervenção, 3 se nomearam de tal forma (Adrião, Menezes, Souza, \& Falcão, 2017; Silva, Silva, Sicari, \& Pereira, 2014; Vieira, Dias, \& Pereira, 2016); e um deles (Moretto, \& Terzis, 2013) consideramos 
como pesquisa-intervenção por entendermos como estudo de investigação participativa, pela interferência coletiva na produção de micropolíticas de transformação social (Aguiar, \& Rocha, 2007). Apenas um estudo (Souza, \& Santos, 2009) autodenominou-se como pesquisa empírica.

Outro aspecto importante é o grande número de trabalhos fundamentados nos referenciais teóricos da psicanálise: 7 das 10 publicaçôes (Carvalho et al., 2008; Cunha \& Lima, 2013; Moretto, \& Terzis, 2013; Rosário, 2010; Sardenberg, 2008; Souza, 2011; Souza, \& Santos, 2009). As publicaçôes de Silva et al. (2014) e de Vieira et al. (2016) utilizaram como referencial teórico a Psicologia HistóricoCultural, e a publicação de Adrião et al. (2017) teve como aporte as teorias feministas e a Psicologia Social. Diante disso, para melhor compreendermos como esses estudos pensaram e utilizaram a finalidade do grupo de acordo com seus referenciais teóricos, faz-se necessária uma caracterização dos diferentes tipos de grupos que foram utilizados nos artigos recuperados.

\subsection{Caracterização dos tipos de grupos}

Todos os estudos foram realizados em instituições (quadro 2), e a maioria deles ( $\mathrm{n}=6$ ) desenvolveu-se em contextos de saúde (Carvalho et al., 2008; Moretto, \& Terzis, 2013; Sardenberg, 2008; Silva et al., 2014; Souza, 2011; Souza, \& Santos, 2009). Dois estudos ocorreram no contexto escolar (Adrião et al., 2017; Cunha \& Lima, 2013), em que um foi realizado em contexto socioeducativo (Rosário, 2010) e o outro em contexto social (Vieira et al., 2016). Essas caracterizações podem ser observadas no quadro 2 , a seguir. 


\section{Quadro 2 - Caracterização da finalidade do grupo e seus participantes conforme os artigos} recuperados

\begin{tabular}{|c|c|}
\hline Artigo & Participantes \\
\hline $\mathrm{A} 1$ & $\begin{array}{l}\text { Oito jovens em tratamento } \\
\text { ambulatorial, em um hospital } \\
\text { universitário }\end{array}$ \\
\hline $\mathrm{A} 2$ & $\begin{array}{l}\text { Adolescentes em privação de } \\
\text { liberdade, em uma instituição de } \\
\text { medida socioeducativa }\end{array}$ \\
\hline A3 & $\begin{array}{l}\text { Adolescentes do sexto ano do ensino } \\
\text { fundamental de uma escola particular }\end{array}$ \\
\hline A4 & $\begin{array}{l}\text { Jovens em uma unidade básica de } \\
\text { saúde (UBS) de um Município do } \\
\text { Estado de Minas Gerais }\end{array}$ \\
\hline A5 & $\begin{array}{c}\text { Jovens de } 12 \text { a } 18 \text { anos em um Centro } \\
\text { de Referência de Assistência Social, } \\
\text { em uma cidade no interior de Minas } \\
\text { Gerais }\end{array}$ \\
\hline A6 & $\begin{array}{l}\text { Jovens em um ambulatório do } \\
\text { Instituto de Psiquiatria da UFRJ }\end{array}$ \\
\hline A7 & $\begin{array}{l}\text { Oito jovens universitários } \\
\text { diagnosticados com fobia social em } \\
\text { tratamento ambulatorial, em um } \\
\text { hospital universitário }\end{array}$ \\
\hline
\end{tabular}

Jovens estudantes do ensino médio de A8 escolas públicas das cidades de Cabo de Santo Agostinho e Ipojuca

Sete adolescentes, em torno de 15 A9 a 16 anos, em Hospital do Servidor Público Municipal

\section{Finalidade do grupo}

Grupo terapêutico: continente para vivências emocionais dos participantes.

Grupo temático: favorecer a circulação da palavra e a reflexão de conteúdos, sugeridos pelos adolescentes, como maneira de significar seus atos.

Dispositivo clínico de conversação: dissolver o saber de especialista e promover um espaço para circular a palavra, de modo que os discursos, pelos atos de fala, tencionem o universal e o particular, levando a produzir sujeitos.

Grupo de discussão: possibilitar um novo olhar sobre o mundo físico e social no qual formamos uma consciência subjetiva e cultural.

Grupo com jovens: proporcionar espaço de reflexão acerca da realidade, permitindo pensar em ações que modifiquem, de alguma forma, suas vidas.

Grupo de acolhimento: intervenção institucional, propiciando acesso direto e rápido a um atendimento especializado.

Grupo terapêutico: buscar autoconhecimento de seus participantes e a promoção de mudança da personalidade.

Grupo de formação (pesquisa-intervenção): favorecer o lugar de sujeitos ativos aos jovens e às jovens, onde estes e estas pudessem ter o poder de fala e possibilidades de construção de um conhecimento reflexivo acerca do cotidiano, tendo as metodologias participativas como ferramenta.

Grupo de psicoterapia: ferramenta estratégica de trabalho para construção das subjetividades em tempos de vivências de sentimento de exílio interior. 
Oito adolescentes, entre 14 e 16 anos, A10 em um Centro de Atenção Psicossocial da Infância e Adolescência em uma cidade do Estado de São Paulo
Grupo: investigar e compreender as produções do inconsciente dos adolescentes do grupo para que, com base na experiência de grupo, compreendam seu funcionamento, seu próprio modo de ser em grupo, assim como o do outro.

Fonte: elaborado pelas autoras.

O grupo, ao estar inserido em uma instituição, pode ser permeado por alguns entraves institucionais, e sete deles problematizaram, de diferentes formas, essa questão. Em seu estudo, Rosário (2010, p. 67) aponta que os "mecanismos de controle e de disciplina" do contexto socioeducativo, onde realizou o grupo, tinham implicações diretas para formação de modos de subjetivação dos adolescentes que ali se encontravam. A configuração institucional trouxe desafios durante os encontros grupais, principalmente pelos jovens considerarem o grupo como espaço também normativo. Diante disso, a autora enfatiza a necessidade de prescriçôes que visem ao cuidado, considerando a história e a singularidade dos sujeitos e não a "ordem e disciplinamento" da instituição.

Cunha e Lima (2013) problematizam a necessidade de o ambiente escolar ofertar "escuta analítica", no intuito de oferecer espaços em que os sujeitos possam nomear o próprio mal-estar e construir um saber possível sobre seus impasses.

Silva et al. (2014) relatam a dificuldade de construção de um grupo de jovens dentro de UBS, já que o local nunca foi ocupado por esse público e, em consequência disso, as autoras trazem algumas provocações, por meio de leituras de materiais, para a instituição em relação às suas estratégias e as concepções de saúde compreendidas pelo serviço.

Nota-se que, apesar de as Diretrizes nacionais para a atenção integral à saúde de adolescentes e jovens na promoção, proteção e recuperação da saúde (Ministério da Saúde, 2010) ressaltarem sobre a primazia das atividades grupais de educação em saúde com jovens, essa prática ainda não parece estar consolidada, visto que não ocorre em alguns contextos de saúde. Alguns artigos relacionados aos contextos de saúde enfatizaram a ausência de atividades grupais nesses espaços.

Carvalho et al. (2008) também apontam a dificuldade de implantação de um novo dispositivo de atendimento grupal, visto que a instituição hospitalar onde realizaram seu estudo utilizava o grupo ou para construção de diagnósticos ou para psicoterapia. Já Sardenberg (2008) ressalta o desafio em continuar com os grupos, devido à redução e mudança de profissionais na instituição hospitalar em que relatou sua experiência. 
Além dos desafios da criação de uma nova modalidade de atendimento, das normas institucionais e redução de profissionais que pudemos acompanhar até aqui, Vieira et al. (2016) relatam a dificuldade de realizarem o estágio, que tinha a proposta de um grupo, dentro de uma instituição de assistência social, visto que os profissionais que ali trabalhavam realizavam o grupo de maneira divergente. Eles normalmente aconteciam com mulheres e tinham temáticas específicas. Essas diferenças fizeram com que o estágio não fosse prontamente aceito.

Conforme podemos perceber, ainda existem diversos empecilhos nos contextos com possibilidades para atuação grupal. Mediante esse cenário e entendendo que as DCN para os cursos de Psicologia (Resolução no 5, 2011) preveem, para formação do psicólogo, habilidades e competências profissionais voltadas para práticas grupais, cabe ressaltar e questionar sobre o que as universidades têm proporcionado aos estudantes em sua formação, já que as práticas grupais estão permeadas de dificuldades para que ocorram.

Ainda no quadro 2, os grupos foram nomeados de diferentes maneiras e apresentaram diversas finalidades. Com o objetivo de buscarmos aproximações entre as compreensões de grupos dos estudos, na tentativa de analisar e entender suas semelhanças e diferenças, ressaltamos três aspectos relevantes. São eles:

1) espaço de circulação da palavra;

2) espaço de troca e possibilidade de transformação;

3) grupo como espaço terapêutico.

\subsection{Espaço de circulação da palavra}

No que tange ao primeiro aspecto em relação à finalidade do grupo como espaço de circulação da palavra, seis artigos ressaltaram que conversar, dialogar e falar permitiram a construção de um espaço conversacional e de trocas (Adrião et al., 2017; Carvalho et al., 2008; Cunha \& Lima, 2013; Rosário, 2010; Silva et al., 2014; Vieira et al., 2016).

Ao promover a circulação da palavra, é possível o "favorecimento da reflexão", visando ao cuidado com os adolescentes, as adolescentes, bem como considerálos como "sujeitos com história e singularidade", como traz Rosário (2010, p. 74). Nesse sentido, Cunha e Lima (2013, p. 516) destacam que, quando a palavra circula, ela pode fazer com que "algo novo surja a partir do convite a fala", o que abre a possibilidade para que cada sujeito fale de sua própria adolescência. Ainda nesse mesmo aspecto, Silva et al. (2014, p. 25) apontam que a possibilidade de 
fala pode produzir um entendimento sobre si, assim como permitir "ressignificar suas vivências e produzir força em sua voz", possibilitando "outras formas de ver e estar no mundo".

Vieira et al. (2016, p. 59) também ressaltam que valorizar a experiência dos sujeitos contribui para que "estes reconheçam sua identidade", além de ser uma maneira de "legitimar suas queixas". Dessa forma, os diálogos podem se tornar "promotores de saúde". Além disso, as autoras ressaltam que, pelo grupo, os jovens, as jovens puderam vivenciar "um processo de reconhecimento de si próprios e da realidade social, econômica e cultural que estavam inseridos" (p. 61). Carvalho et al. (2008, p. 43) apontam que a "ênfase no poder falar/ ser escutado" constitui-se como um dos "princípios fundamentais do grupo", já que abre a possibilidade de "reflexão, de questionar-se e ver-se questionado pelo outro". Por fim, Adrião et al. (2017) também enfatizam o conversar como "possibilidade de reflexão".

As visões apresentadas anteriormente concordam em relação à potencialidade que o espaço de circulação da palavra pode promover em um grupo e destacam que esse espaço é construído juntamente com todos os membros envolvidos. Além disso, temos a compreensão de que, ao abrir a possibilidade de conversar/ falar/dialogar, esses espaços se tornam produtores de reflexôes, considerando os sujeitos em sua totalidade. Entretanto percebemos certa naturalização dos sujeitos participantes dos grupos visto que são considerados apenas aspectos de sua singularidade, deixando de considerar a perspectiva histórica sobre o momento que vivem, e pouca contextualização, ou seja, suas histórias de vida e suas condições sociais (poder aquisitivo, gênero, etnias raciais, onde residem, com quem residem, entre outras) deixaram de ser ressaltadas.

Além da importância de (re)conhecer a história de cada membro que constitui o grupo, é necessário compreendermos que esses sujeitos estão imersos em relações sociais de produção, as quais são constituintes de suas subjetividades, uma vez que essas relações expressam um conjunto de características históricas que permeiam a sociedade em que vivemos. Conforme aponta Lane (1984), "o grupo, tanto na sua forma de organização como nas suas ações, reproduz ideologia, que, sem um enfoque histórico, não é captada” (pp. 81-82), ou seja, é necessário um olhar mais amplo sobre a inserção do grupo em seus diversos marcadores sociais.

\subsection{Espaço de troca e possibilidade de transformação}

A concepção de grupo como espaço de troca ganha destaque em oito artigos (Adriāo et al., 2017; Cunha, \& Lima, 2013; Moretto, \& Terziz, 2013; Sardenberg, 
2008; Silva et al., 2016; Souza, 2011; Souza, \& Santos, 2009; Vieira et al., 2016). As trocas são compreendidas de diferentes maneiras. Souza (2011, p. 6) destaca, em seu artigo, o momento em que os participantes começam a interagir, visto que, nos encontros iniciais, predominaram "desesperança e resistência" entre os participantes em relação ao "medo da ruptura do sigilo" e, segundo a autora, a interação é marcada pela quebra da resistência. Souza e Santos (2009, p. 279) também ressaltam a questão da dificuldade dos participantes do grupo de "se expressarem espontaneamente". Entretanto, os autores e as autoras apontam que essa dificuldade pode estar atrelada ao receio dos jovens de serem punidos. Nesse mesmo sentido, compreendendo que o grupo tem seus desafios e limitações, Adriāo et al. (2017, p. 9) apontam que aprenderam com o grupo que há limites para o que "pode e/ou é possível ser dito ou não nos encontros", mas que, ao mesmo tempo, foi apontado pelos jovens como "o único lugar onde podiam falar abertamente".

Apesar das questôes citadas anteriormente, Cunha e Lima (2013, p. 516) apontam que as trocas, ou seja, "o endereçamento ao Outro permite a invenção de uma modalidade de resposta inédita, o encontro de um nome para a sua dificuldade". Silva et al. (2014, p. 26) também entendem as trocas como potências de construção de outros entendimentos, vislumbrando "perspectivas de ação". Ainda nesse mesmo aspecto, Vieira et al. (2016, p. 65) compreendem os espaços de troca como possibilitadores de um processo de "desconstrução de crenças" e complementam que essas afetações empoderam os sujeitos a se identificarem como "agentes transformadores" de suas próprias realidades.

Para Sardenberg (2008, p. 136), a dimensão das trocas ou compartilhamento denotam o "caráter ativo" da postura do coordenador do grupo, que implica em estar com/no "mesmo barco" que os jovens. Por último, Moretto e Terzis (2013, p. 30) destacam as trocas e compartilhamentos do grupo como um lugar para a "realização dos desejos reprimidos e de manifestação do inconsciente dos participantes".

As trocas foram compreendidas de diferentes maneiras nos artigos, sejam como desafiantes e, ou, limitantes, sejam como potencializadoras de novas formas de (des)entendimentos, mas podemos perceber que todas elas tornam o grupo potência para transformação. Entretanto a compreensão do grupo como espaço de transformação foi nomeado apenas em um artigo (Souza, 2011).

Pelos artigos, entendemos que o relacionar com os outros é um importante potencializador para que as transformaçōes ocorram, mesmo que tenham seus desafios. Entretanto, o que significa o ato de (não) falar com os outros em um espaço grupal? Para que essas trocas sejam compreendidas, é necessário que 
elas estejam contextualizadas. Sobre esse aspecto, Martins (2007) sugere que "devemos considerar que todo grupo existe sempre dentro de instituiçôes, que vão desde a família, a fábrica, a universidade até o próprio Estado" (p. 77), o que implica em (des)encontros entre diferentes sujeitos. Diante disso, é necessário um olhar mais amplo sobre as relações/trocas que emergem no grupo, pois só conseguiremos entender o que acontece no "aqui e agora" com base em uma dimensão historicamente compreendida. Assim, percebemos que há uma (re) produção de não identificação sobre os processos pelos quais os grupos foram se produzindo.

\subsection{Espaço terapêutico}

O aspecto do grupo como espaço terapêutico foi destacado em quatro artigos (Carvalho et al., 2008; Moretto, \& Terzis, 2013; Souza, 2011; Souza \& Santos, 2009). Para Souza (2011), suas análises foram os determinantes para que ela pudesse compreender as transformaçôes que foram ocorrendo durante os encontros do grupo e nomeá-lo como espaço terapêutico. Foram essas mesmas percepções e a literatura de sua área que permitiram que Souza e Santos (2009) identificassem e nomeassem o grupo como grupo terapêutico.

A compreensão do grupo como um dispositivo clínico potente, através do esclarecimento das demandas e das intervençôes clínicas, foi o que levou Carvalho et al. (2008) a identificarem a produção de efeitos terapêuticos ao longo dos encontros. Já para Moretto e Terzis (2013), a promoção de autoconhecimento e o alívio emocional dos participantes do grupo foram os aspectos que os levaram a concluir que o grupo se constituiu em um dispositivo terapêutico.

Assim, considerando as diversas perspectivas sobre grupos e como as instituições de formação os compreendem, qual a finalidade deles para Psicologia? O que os psicólogos têm feito de grupo? Por desta revisão, pudemos notar que ainda perdura uma concepção de grupo que descontextualiza seus sujeitos envolvidos, assim como o que acontece no espaço. De toda prática grupal, a ênfase dos estudos se destina ao ato de conversar e compartilhar com o outro, como se esses aspectos fossem exclusivamente o cerne para constituição de um grupo e estivessem além e aquém dos jovens, das jovens que ali estão, bem como de suas histórias.

\section{CONSIDERAÇÕES FINAIS}

A revisão integrativa de literatura que realizamos buscou explorar a maneira 
como os estudos em Psicologia caracterizam e constituem a perspectiva grupal com jovens, indicando quais são os tipos de estudos, onde foram realizados, qual a finalidade do grupo e como isso tem sido compreendido. Diante disso, pudemos identificar quais as tendências desses estudos nessas áreas, bem como identificar algumas limitações.

A partir do objetivo proposto, entendemos que a prática grupal com jovens tem acontecido e tem como principal objetivo proporcionar um espaço de fala e trocas entre os sujeitos inseridos. Entendendo que a Psicologia tem diversas perspectivas para pensar o grupo, prevalece uma concepção de naturalização, em que os jovens, na maioria das vezes, são descontextualizados e o caráter conversacional enfatizado.

Outro aspecto que nos chama a atenção é o número de publicações sobre práticas grupais com jovens. Dez estudos em língua portuguesa foram produzidos nos últimos dez anos. Nesse cenário, tornam-se necessários futuros estudos que enfatizem a metodologia grupal com jovens, visto que é uma prática visada pelas DCN dos cursos de Psicologia, bem como pelas Diretrizes nacionais para a atenção integral à saúde de adolescentes e jovens na promoção, proteção e recuperação da saúde.

Dessa maneira, este estudo contribui para refletirmos sobre o que nós, psicólogos, temos produzido e entendido sobre grupos com jovens e, até mesmo, o que as instituições de formação têm ofertado sobre grupo em seus currículos, tendo em vista que a prática grupal com jovens ainda não está presente em algumas instituições em que ela se faz necessária e, quando ela existe, que tipo de grupo estamos produzindo com esses sujeitos.

Vale ressaltar, não obstante, as limitações no decorrer do desenvolvimento desta revisão. A primeira delas se refere ao fato de que as informações foram restringidas pelas publicações em língua portuguesa dos últimos dez anos. Outras línguas e um maior recorte de tempo poderiam estender o corpus de análise. Além disso, as publicaçôes poderiam ter sido evidentemente ampliadas, caso tivéssemos incluído mais bases de dados. Outro aspecto limitante foram os descritores utilizados para realizar a busca. Compreendemos que existem trabalhos que têm como foco intervenções coletivas, entretanto não utilizam os termos "grupo" ou "grupos" nas publicações, e, por isso, não estão inclusos nesta revisão.

Por fim, ter envolvido outras áreas de conhecimento, como Enfermagem e Pedagogia, entre outras, ter-nos-ia permitido uma revisão mais abrangente. Ressaltamos esses aspectos, contudo, como possibilidade de futuros estudos. 


\section{REFERÊNCIAS}

Adrião, K. G., Menezes, J. A., Souza, L. B., \& Falcão, R. (2017). Mulheres e homens jovens: gozos e interdições, poder e desigualdades. Psicologia \& Sociedade, 29, e153790. Recuperado a partir de http://www.scielo.br/pdf/ psoc/v29/1807-0310-psoc-29-e153790.pdf

Aguiar, K. F., \& Rocha, M. L. (2007). Micropolítica e o exercício da pesquisaintervenção: referenciais e dispositivos em análise. Psicologia: Ciência e Profissão, 27(4),648-663. Recuperado a partir de http://www.scielo.br/pdf/pcp/v27n4/ v27n4a07.pdf

Barros, R. B. (2007). Grupo: a afirmação de um simulacro. Porto Alegre: Sulina, Editora da UFRGS.

Boris, G. D. J. B. (2014). Elementos para uma história da psicoterapia de grupo. Revista da Abordagem Gestáltica, 20(2), 206-212. Recuperado a partir de http:// pepsic.bvsalud.org/pdf/rag/v20n2/v20n2a08.pdf

Carvalho, C. A. C., Medina, R. M., Bossetto, S., \& Cruz, T. A. (2008). Grupo de acolhimento: relato da experiência. Psicologia Revista, 17(1/2), 43-58. Recuperado a partir de https://revistas.pucsp.br/psicorevista/article/ view/ 18020

Cunha, C. F., \& Lima, N. L. (2013). A escuta de adolescentes na escola: a sexualidade como sintoma escolar. Estilos Clínicos, 18(3), 508-517. Recuperado a partir de http://pepsic.bvsalud.org/pdf/estic/v18n3/v18n3a5.pdf

Dalla Vecchia, M. (2011). Trabalho em equipe na atenção primária à saúde: o processo grupal como unidade de análise da dialética cooperação-trabalho coletivo. (Tese de Doutorado). Programa de Pós-Graduação em Medicina, Universidade Estadual Paulista, Botucatu.

Fernandes, L. V. (2015). O processo grupal como resistência ao sofrimento e ao adoecimento docente: um estudo à luz da perspectiva histórico-dialética. (Tese de Doutorado). Programa de Pós-Graduação em Psicologia, Universidade de São Paulo, São Paulo.

Lane, S. T. M. (1984). O processo grupal. In S. T. M. Lane, \& W. Codo (Orgs.), Psicologia social: o homem em movimento. (13a ed.). (pp. 78-98). São Paulo: Brasiliense. 
Maireno, D. P., Sei, M. B., \& Zanetti, S. A. S. (2016). O ensino da técnica grupal na graduação em Psicologia. Vinculo - Revista do NESME, 13(1), 2032. Recuperado a partir de http://pepsic.bvsalud.org/pdf/vinculo/v13n1/ v13n1a03.pdf

Martín-Baró, M. (1996). Sistema, grupo y poder. (3a ed.). San Salvador: UCA.

Martínez, M. C., \& Paterna, C. (2010). Manual de Psicología de los grupos. Madrid: Síntesis.

Martins,S.T.F.M.(2007).Psicologiasociale processogrupal:acoerênciaentrefazer, pensar e sentir em Sílvia Lane. Psicologia \& Sociedade, 19(2),76-80. Recuperado a partir de https://repositorio.unesp.br/bitstream/handle/11449/28926/ S0102-71822007000500022.pdf? sequence $=1$ \&isAllowed $=y$

Ministério da Saúde. (2010). Secretaria de Atenção em Saúde. Departamento de Ações Programáticas Estratégicas. Diretrizes nacionais para a atenção integral à saúde de adolescentes e jovens na promoção, proteção e recuperação da saúde. Brasília: Ministério da Saúde. (Série A. Normas e Manuais Técnicos). Recuperado a partir de http://bvsms.saude.gov.br/bvs/publicacoes/diretrizes_ nacionais_atencao_saude_adolescentes_jovens_promocao_saude.pdf

Moretto, C. C., \& Terzis, A. (2013). Uso de mitos gregos em um grupo psicanalítico com adolescentes. Revista da SPAGESP, 14(1), 30-42. Recuperado a partir de http://pepsic.bvsalud.org/pdf/rspagesp/v14n1/v14n1a05.pdf

Petrovski, A. V. (1984). Personalidad, actividad y colectividad. Buenos Aires: Cartago.

Resolução no 5, de 15 de março de 2011. (2011, 15 março). Institui as Diretrizes Curriculares Nacionais para os cursos de graduação em Psicologia. Brasília: Ministério da Educação, Conselho Nacional de Educação, Câmara de Educação Superior. Recuperado a partir de portal.mec.gov.br/index.php?option=com docman\&view=download\&alias=7692-rces005-11-pdf\&Itemid=30192

Rodrigues, D. S. (2017). Grupo como dispositivo socioeducativo-dialógico: reflexōes sobre uma intervenção com adolescentes em meio aberto. (Tese de Doutorado). Programa de Pós-Graduação em Psicologia, Universidade de Brasília, Brasília.

Rosário, A. B. (2010). Grupo com adolescentes em privação de liberdade: circulação da palavra como possibilidade de ressignificação do ato infracional. Revista SPAGESP, 11(11), 66-76. Recuperado a partir de http://pepsic.bvsalud. org/pdf/rspagesp/v11n1/v11n1a08.pdf 
Sardenberg, M. L. C. (2008). O encontro nos grupos: efeitos de um conceitoferramenta para o dispositivo grupal. Psicologia Revista, 17(1/2), 131-140. Recuperado a partir de https://revistas.pucsp.br/index.php/psicorevista/ article/view/18026

Scorsolini-Comin, F. (2014). Guia de orientação para iniciação científica. São Paulo: Atlas.

Silva, B. Z., Silva, L. S., Sicari, A. A., \& Pereira, E. R. (2014). Juventude e movimentos na/da cidade: experienciando a promoçãa de saúde. Revista Psicologia e Saúde, 6(2),20-27. Recuperado a partir de http://pepsic.bvsalud. org/pdf/rpsaude/v6n2/v6n2a04.pdf

Souza, L. V. (2011). Ansiedade social: construção de um espaço grupal de comunicação e segurança. Revista SPAGESP, 8(1), 1-7. Recuperado a partir de http://pepsic.bvsalud.org/pdf/vinculo/v8n1/a04.pdf

Souza, L. V., \& Santos, M. A. (2009). Grupo terapêutico para jovens com fobia social. Revista Brasileira de Crescimento e Desenvolvimento Humano, 19(2), 269280. Recuperado a partir de http://pepsic.bvsalud.org/pdf/rbcdh/v19n2/08. pdf

Souza, M. T., Silva, M. D., \& Carvalho, R. (2010). Revisão integrativa: o que é e como fazer? Einstein, 8(1), 102-106. Recuperado a partir de http://www.scielo. $\mathrm{br} / \mathrm{pdf} /$ eins/v8n1/pt_1679-4508-eins-8-1-0102.pdf

Vieira, A. P. A., Dias, C. N., \& Pereira, E. R. (2016). "Dá até pra fazer poesia": o recurso estético disparando reflexões e potência. Revista Psicologia e Saúde, 8(2), 55-66. Recuperado a partir de http://pepsic.bvsalud.org/pdf/rpsaude/ $\mathrm{v} 8 \mathrm{n} 2 / \mathrm{v} 8 \mathrm{n} 2 \mathrm{a} 05 . \mathrm{pdf}$

Vigotski, L. S. (1996). Psicologia del adolescente. In Obras escogidas. (Vol. 4, pp. 9-248). Madrid: Visor Dis.

Zanella, A. V., \& Pereira, R. S. (2001). Constituir-se enquanto grupo: a ação de sujeitos na produção do coletivo. Estudos de Psicologia, 6(1), 105-114. Recuperado a partir de http://www.scielo.br/pdf/epsic/v6n1/5337.pdf 